\title{
ROBÔ SEGUIDOR DE LINHA PARA COMPETIÇÕES
}

\author{
Otávio de Souza Martins Gomes ${ }^{1}$ \\ Rafael Vinícius Tayette de Nóbrega ${ }^{2}$ \\ Lucas Vinícius Ribeiro ${ }^{3}$ \\ Rayane Rainer ${ }^{4}$
}

\begin{abstract}
RESUMO
Este projeto tem como objetivo montar um robô que consiga seguir a trajetória de uma linha de cor branca ou preta em um fundo de cor oposta à da linha. O seu sistema para detecção da linha conta com o uso de sensores de luz infravermelha para detectar o sinal refletido a partir de um diodo emissor apropriado. As superfícies pretas têm a propriedade de absorver radiações de todos os comprimentos de onda na faixa visível.
\end{abstract}

Palavras-chaves: Microcontrolador. Robô. Sensor. Arduino. Seguidor de linha.

\section{ROBOT LINE FOLLOWER FOR COMPETITIONS}

\begin{abstract}
This project aims to build a robot which is capable of following a white or black colored line having its opposite color as background. The system for the line detection uses infrared light sensors to detect the reflected signal, which is emitted from an infrared LED. The black surfaces have the property of absorbing radiation of all waves' length on the visible line.
\end{abstract}

Keywords: Microcontroller. Robot. Sensor. Arduino. Line follower.

\section{INTRODUÇÃO}

Robôs são utilizados para exploração de locais onde não há segurança para humanos. Eles são criados para se comportarem de forma autônoma, sem a necessidade de intromissão de um humano. A tecnologia destes robôs é, de forma geral, complexa, não sendo trivial sua compreensão para pessoas leigas.

\footnotetext{
${ }^{1}$ Doutorando em Engenharia Elétrica pela Universidade Federal de Itajubá (Unifei), mestrado em Engenharia Elétrica pela Unifei e docente efetivo do Instituto Federal de Minas Gerais - Campus Formiga. E-mail: otavio.gomes@ifmg.edu.br.

${ }^{2}$ Doutorando em Engenharia Elétrica pela Escola de Engenharia de São Carlos Universidade de São Paulo (USP). Mestrado em Engenharia Elétrica pela USP e docente efetivo do IFMG - Campus Formiga E-mail: rafael.nobrega@ifmg.edu.br.

${ }^{3}$ Graduando em Engenharia Elétrica pelo IFMG - Campus Formiga: E-mail:

lucas.viniciosribeiro@yahoo.com.br.

${ }^{4}$ Graduanda em Engenharia Elétrica pelo IFMG - Campus Formiga: E-mail: rayanerainer@gmail.com ForSci.: r. cient. IFMG campus Formiga, Formiga, v. 2, n. 2, p. 07-11, jul./dez. 2014.
} 
Para facilitar a compreensão e ajudar na construção deste projeto, é necessário entender os blocos funcionais que se comunicam a fim de fazer o robô realizar uma determinada tarefa.

Um robô seguidor de linha é aquele que tem a capacidade de detectar uma linha desenhada no chão por meio do contraste entre a cor desta linha e a cor do restante do piso. Estes robôs são conhecidos como veículos guiados automaticamente.

\section{DESENVOLVIMENTO PRÁTICO}

\subsection{Desenvolvimentos da estrutura}

Desenvolveu-se um esboço do chassi do seguidor de linha no programa ZWCAD a partir das especificações das competições acadêmicas existentes nesta área de pesquisa e conhecimento. A partir do esboço especificado, foi construída a estrutura do seguidor de linha. Na Fig. 1 pode ser visto o seguidor de linha construído.

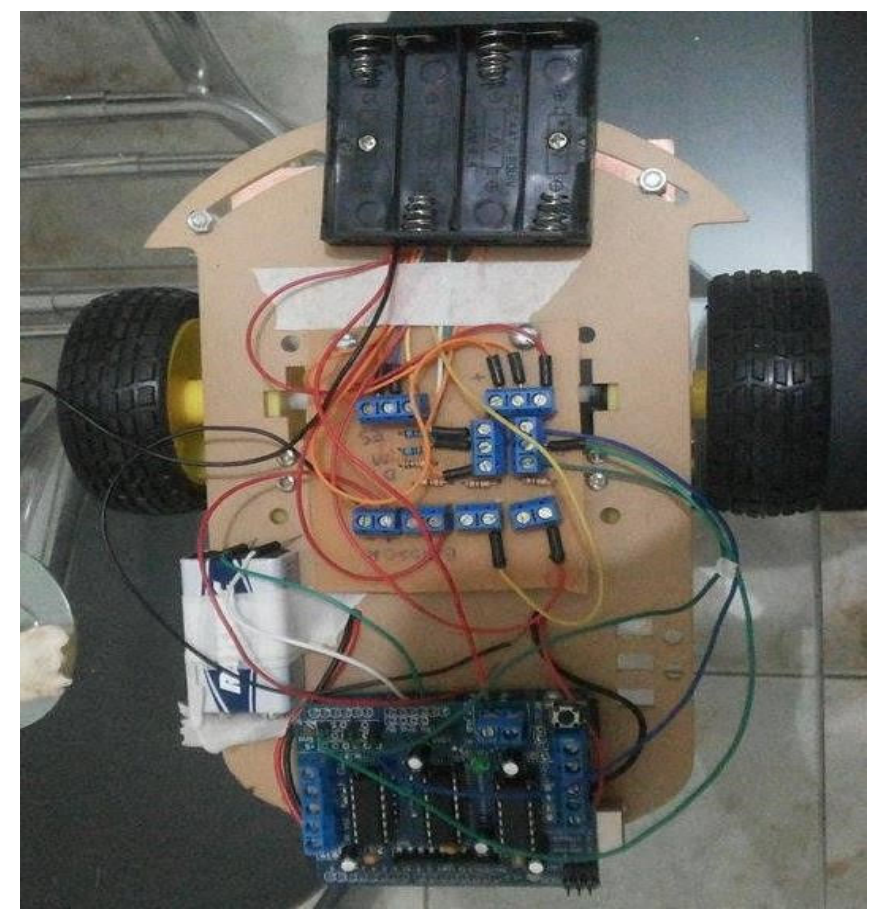

Figura 1 - Protótipo do seguidor de linha Fonte: Elaborado pelos autores.

Uma famosa competição que ocorre no Brasil é realizada pela empresa RoboCore (ROBOCORE, 2014). Seguem, abaixo, as especificações fornecidas nesta competição: 
- o robô não poderá exceder $250 \mathrm{~mm}$ de comprimento, $250 \mathrm{~mm}$ de largura e $200 \mathrm{~mm}$ de altura;

- o robô não poderá possuir nenhum tipo de mecanismo de sucção para aumentar a força normal em relação ao solo;

- a superfície da pista será preta, feita com uma ou mais placas de MDF revestidas com fórmica preta. Portanto, eventuais emendas de placas serão necessárias para compor toda a área do percurso - isso poderá ocasionar desníveis, e a organização tentará minimizá-los da melhor maneira possível, adicionando fita preta em todas as emendas. De qualquer forma, os robôs devem ser capazes de superar tais desníveis $( \pm 1 \mathrm{~mm})$;

- o percurso será indicado por uma linha branca de $19 \pm 1 \mathrm{~mm}$ de largura. O comprimento total da linha será de, no máximo, 60 metros.

\subsection{Desenvolvimento do circuito}

Através de pesquisas em tutoriais disponibilizados por alguns grupos acadêmicos de robótica (UAIRRIOR, 2014; TRÓIA, 2014) e trabalhos acadêmicos (GIOPO, 2013; FATEC, 2013), foi desenvolvido o circuito para este seguidor de linha.

O circuito apresentado na Fig. 2 realiza a captação do sinal dos diodos e envia os dados obtidos para que o Arduino realize o processamento deles (ARDUINO, 2014). Após essa etapa, os motores movimentar-se-ão conforme a posição do carro na pista.

Primeiramente foi feito o circuito no Protoboard, como mostra o esquema abaixo:

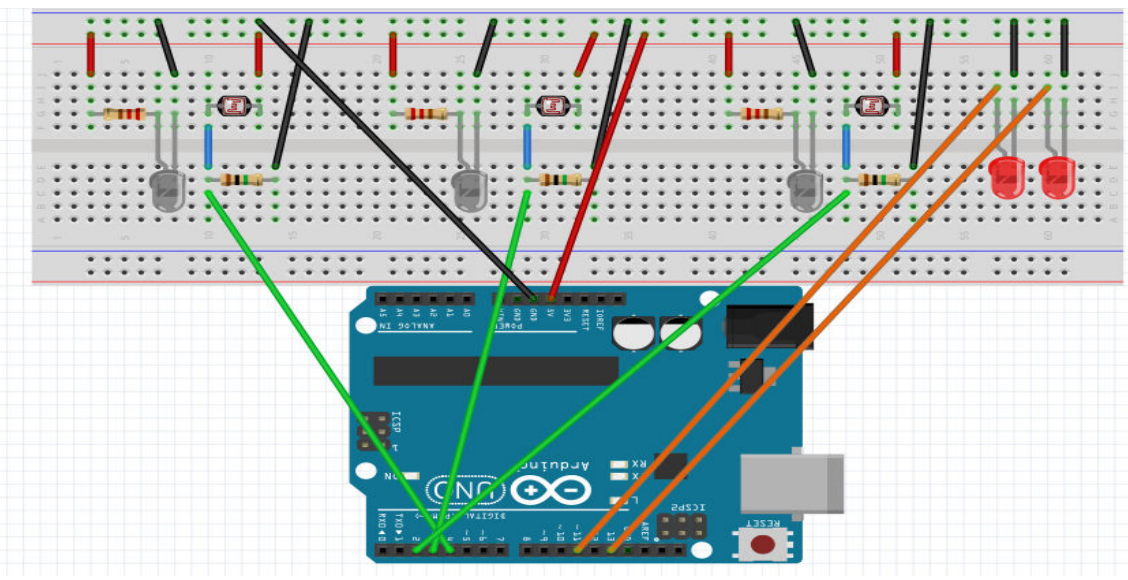

Figura 2 - Circuito de detecção de linha Fonte: Elaborado pelos autores. 
Nesta montagem testaram-se os fotodiodos e os fototransistores. Foram utilizados valores de resistência para que nenhum equipamento fosse danificado e, finalmente, verificouse o funcionamento dos motores, utilizando LEDs.

A tabela a seguir mostra a lista de materiais utilizados no desenvolvimento deste projeto.

Tabela 1 - Materiais utilizados na confecção do projeto

\begin{tabular}{lc}
\hline \multicolumn{1}{c}{ Item } & Quantidade \\
\hline Motor DC com caixa de Redução & 2 \\
Microcontrolador Arduino Mega e Shield & 1 \\
Roda 60 mm de diâmetro & 2 \\
Circuito integrado L298N & 1 \\
Fotodiodo TIL & 3 \\
Placa de Circuito 10x5 & 1 \\
Suporte para 6 Pilhas AA (Arduino) & 1 \\
Pilhas AA & 12 \\
Fototransistores & 3 \\
Compensado de Madeira & 1 \\
Fita adesiva branca & 1 \\
Placa de acrílico 30cm/30cm & 1 \\
Fonte: Elaborado pelos autores. &
\end{tabular}

\subsection{Desenvolvimento de Software}

Com a utilização do microcontrolador Arduino, pôde-se realizar a programação para o correto funcionamento do seguidor de linha.

Os sensores foram utilizados como entradas de dados, e foi necessário realizar a calibragem dos valores de entrada para os sensorbes conseguirem captar o que é a linha e o que faz parte do terreno. A luminosidade e a capacidade de reflexão do terreno influenciam nesta calibração.

Os motores representam as saídas de dados. A correta programação e tratamento dos dados permite que o seguidor de linha execute corretamente as curvas e corrija seu posicionamento, caso venha a perder a linha. Para este último caso, desenvolveu-se, ao algoritmo, a condição de o seguidor usar a sua última ação ou último estado em que havia a leitura de uma linha.

\section{RESULTADOS}

Ao fim do projeto, foram realizados testes nas funcionalidades desenvolvidas. Para o funcionamento do seguidor, sem o auxílio do cabo USB para alimentação, utilizou-se uma 
fonte de $6 \mathrm{~V}$ para as placas de circuito e a ponte $\mathrm{H}$, e uma fonte de $9 \mathrm{~V}$ para alimentação da placa Arduino.

\section{CONCLUSÃO}

O projeto cumpriu os objetivos esperados para o seu desenvolvimento, sendo finalizado durante o período estipulado pela instituição de ensino, e com o modelo final concluído conforme especificado nas seções anteriores.

\section{AGRADECIMENTO}

Os autores agradecem ao Instituto Federal de Educação, Ciência e Tecnologia de Minas Gerais - IFMG o apoio financeiro para o desenvolvimento do projeto de pesquisa descrito neste artigo e aprovado no Edital: 006/2013.

\section{REFERÊNCIAS}

ARDUINO. Arduino playground. Disponível em: $<$ http://playground.arduino.cc/Portugues/ HomePage>. Acesso em: 12 dez. 2014.

FATEC POMPEIA. Disponível em: <https://sites.google.com/a/fatecpompeia.edu.br/ eletronica/projeto-robo-seguidordelinha>. Acesso em: 30 ago. 2013.

GIOPO, L. L. et al. Robô seguidor de linha. 34. f. 2009. Monografia (Graduação em Engenharia da Computação)- Universidade Tecnológica Federal do Paraná, 2009. Disponível em: <http://www.pessoal.utfpr.edu.br/msergio/Monog-09-2-Seguidor-de-linha.pdf $>$. Acesso em: 30 ago. 2013.

ROBOCORE. Disponível em: <http://www.robocore.net/>. Acesso em: 12 dez. 2014.

TRÓIA. Equipe de Robótica. Disponível em: <http://www.nucleoestudo.ufla.br/ troia/index.html>. Acesso em: 12 dez. 2014.

UAIRRIOR. Equipe de Robótica. Disponível em: <http://www.uairrior.com.br/>. Acesso em: 12 dez. 2014.

Recebido em: 16/11/2014

Aprovado em: 28/11/2014

Publicado em: 26/01/2015 